\title{
Plastic Deformation Quantified by Atomic Force Microscopy Measurements for Duplex Stainless Steel under Monotonic and Cyclic Loading
}

\author{
I. Serre ${ }^{1, a}$, D.Salazar ${ }^{1, b}$ and J-B. Vogt ${ }^{1, c}$ \\ ${ }^{1}$ Laboratoire de Metallurgie Physique et Génie des Matériaux, UMR CNRS 8517, Université de \\ Lille 1, 59655 Villeneuve d'Ascq Cedex, FRANCE
}

aingrid.serre@univ-lille.fr, ${ }^{b}$ daniel.salazar@ed.univ-lille1.fr, ${ }^{c}$ jean-bernard.vogt@ensc-lille.fr

\begin{abstract}
Keywords: deformation micromechanisms, AFM, Plasticity, Duplex Stainless Steel
\end{abstract}
\begin{abstract}
By atomic force microscopy, the plastic deformation marks resulting from monotonic and cyclic plastic deformation were analysed to study the plasticity in each phase of Duplex Stainless Steels. In austenite, straight slip bands were observed after monotonic loading. These straight slip bands seem to serve as fatigue extrusion nucleation sites, which are the marks of the accommodation of the cyclic plasticity by the austenite. In ferrite, after monotonic loading, slip bands, could be classified into two different groups depending on whether they result from the bulk activities of ferrite or whether their formation is assisted by the plastic deformation of austenite. It was found that the crystallographic misorientation based on a Kurdjomov-Sachs relationship is the factor controlling one or the other type. After the first 5 loading cycles, the ferrite presents only monotonic plastic marks. This suggests no direct contribution of the ferrite to the accommodation of the cyclic plasticity.
\end{abstract}

\section{Introduction}

The need to provide materials with high strength and high ductility has led to the development of complex microstructure alloys. Multiphase grades including Dual Phase (DP), TRansformation Induced Plasticity (TRIP) or Duplex Stainless Steels (DSS) steels are alloys that contain a mixture of different phases, which then have better properties than those obtained separately by the different phases. DSS, which are generally composed of a roughly equal volume fraction of austenite and ferrite, also exhibit high corrosion resistance due to the large amount of $\mathrm{Cr}$, Ni and Mo. One of the major issues that is often raised is the strain mapping at the micro-meso scale of a strained or stressed specimen or component. There are at least two main factors that make this complicated in that case. Firstly, the two phases of a DSS have a different crystallographic structure and a more or less different chemical composition, and, different in hardness or toughness. Secondly, the type of mechanical solicitation, monotonic or cyclic, strongly influences the individual response of the phases. Under monotonic straining, both austenite and ferrite requires, at a moderate rate, an increasing loading with the increasing strain. However under cyclic loading, a hardening or cyclic softening occurs and this depends on the metallurgical properties of the considered phase. For instance, a single phased austenitic steel can exhibit either cyclic softening or cyclic hardening according to the nitrogen content. Though complex, the need to understand the relationship between microstructure and mechanical resistance of structural alloys is necessary for better using the materials or for increasing their performance.

Transmission Electron Microscopy (TEM) can provide accurate images of the dislocation substructures, was not successful because the information is too qualitative, localised and originates from a very small portion of the material. Moreover, it needs special preparation of thin foils and cutting the specimen. Using the channelling contrast of backscattered electrons in a scanning electron microscope (SEM) [1,2] allows dislocation distributions to be imaged on larger areas containing several grains. Promising techniques are those which can combine high resolution analysis of plastic deformation marks and large areas of analysis with a high number of grains at 
different locations of the specimen without destroying the specimen. Vignal et al. [3] obtained fine results using nanoindentation and point grids deposited by electron beam lithography as tools for the measurements of matter displacement but the number of grains investigated was small. Since plastic deformation is a bulk process that involves shearing of the crystallographic planes, metal extrusion at the external surface occurs, the so called slip bands. The latter contain individual steps, each one originated from the intersection of an active slip system with the surface. Imaging at the slip bands high resolution can be done only using Field Electron Gun Scanning Electron Microscopy (FEG-SEM) and Atomic Force Microscopy (AFM). AFM has the advantage that it does not involve any electron matter interactions as is the case for SEM. Secondary electrons images of tips or sharp edges are sometimes difficult to obtain due to their high emissivity and resulting over brightness. The second advantage of AFM is that the z-coordinate can be accurately measured during the scanning of the surface in the $\mathrm{x}$ and $\mathrm{y}$ directions. Theoretically the resolution reaches the tenth of nm but practically is larger than this. In single phased materials, the benefit of the high resolution images acquired by AFM has been used successfully as a complementary method for investigating plasticity [4-6]. In dual phased materials, AFM has been very scarcely employed.

The aim of this work is to investigate the plastic deformations marks resulting from monotonic and cyclic plastic deformation in each phase of a $50 \%$ ferrite $-50 \%$ austenite Duplex Stainless Steel to evaluate local strain partitioning. Both attributes of AFM, high resolution image and numerical information of position will be used to assess the changes at the surface of the material due to the plastic deformation. Two different AFM modes will be employed, working either in contact mode or in tapping mode. Topographic and signal error (experimental derivate of the topographic image) AFM images will be considered. The first image provides topographic information, like the slip band spacings and the slip band heights whereas the second image instantaneously reflects the variations in forces and allows a clear visualization of the slip line features. Electron Backscattered Diffraction (EBSD) will also be used to measure crystallographic orientation to aid in the interpretation of the results.

\section{Materials}

The materials used in this study were High Nitrogen Duplex Stainless Steels $(0.25 \%$ wt $\%$ nitrogen) either supplied by Usinor Industeel, France (UR52N+) or by Böhler Edelstahl, Austria (BöA911). The steels have the chemical composition given in Table 1 and their microstructure consists of a ferrite matrix and austenite islands elongated in the rolling direction (Figure 1).

\begin{tabular}{|c|c|c|c|c|c|c|c|}
\hline & $\mathrm{Cr}$ & $\mathrm{Ni}$ & $\mathrm{Mo}$ & $\mathrm{Mn}$ & $\mathrm{N}$ & $\mathrm{Si}$ & $\mathrm{Fe}$ \\
\hline UR25N+ & 24.81 & 6.56 & 3.71 & 0.98 & 0.24 & 0.36 & Bal. \\
\hline BöA911 & 25.3 & 7.16 & 3.54 & 0.48 & 0.25 & 0.22 & Bal. \\
\hline
\end{tabular}

Table 1: Chemical composition of the studied Duplex Stainless Steels (wt\%)

The volume fraction of $\alpha$ and $\gamma$ phases was about 50.6\%/49.4\% and 51.2\%/48.8\% respectively for the UR52N+ and the BöA911. Table 2 shows the mean grain diameter for $\alpha$ and $\gamma$ determined in the rolling direction by Electron Back-Scattered Diffraction (EBSD) measurements. Table 3 gives the micro hardness HV10 of both materials for the austenite and the ferrite. It is important to note that for the both materials, the two phases had a random distribution.

Previous studies [7] showed that the monotonic behaviour and the cyclic behaviour of both materials are similar in terms of cyclic accommodation and of fatigue resistance. 

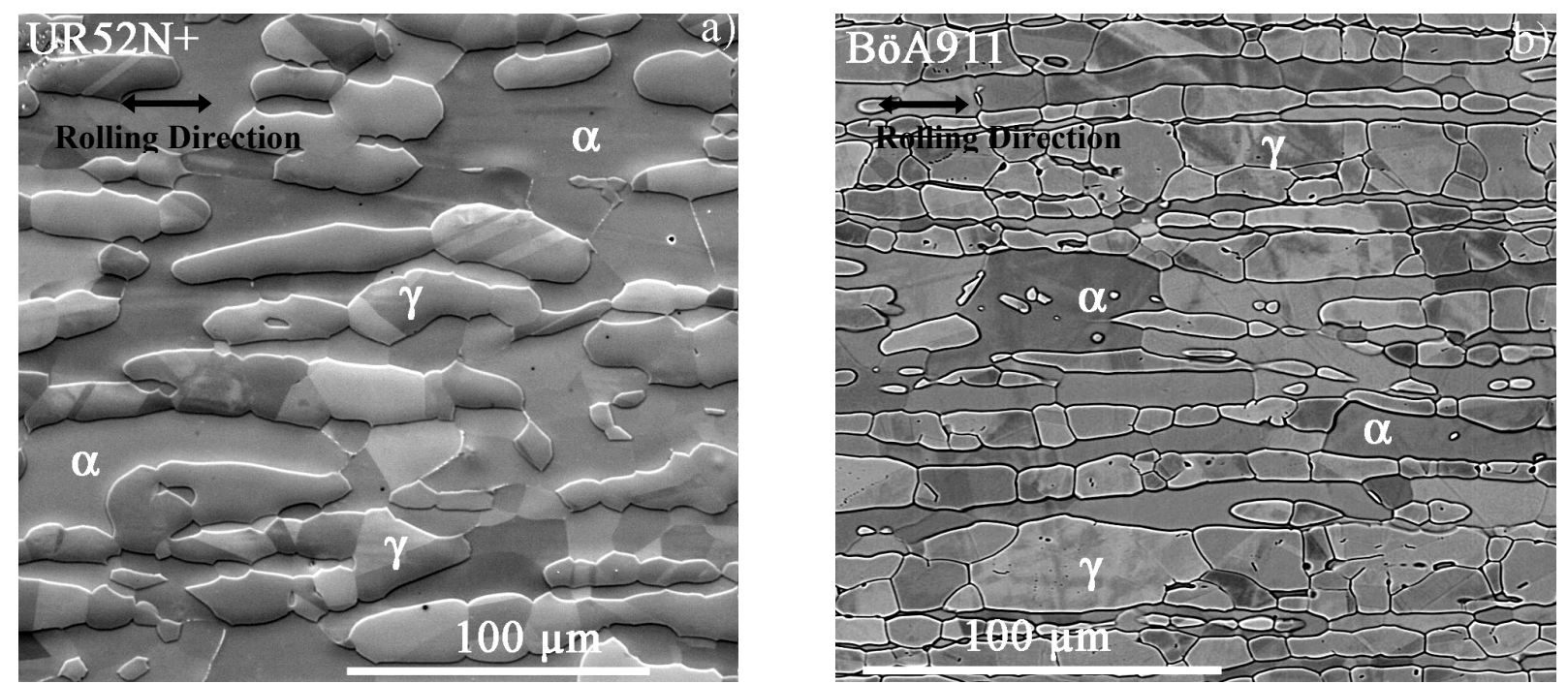

Figure 1: SEM images of the microstructure of the two studied Duplex Stainless Steels:

a) UR52N+, b) BöA911

\begin{tabular}{|c|c|c|}
\hline & $\alpha$ & $\gamma$ \\
\hline UR25N+ & $16.4 \pm 11$ & $11.1 \pm 5.2$ \\
\hline BöA911 & $10.0 \pm 6.2$ & $6.5 \pm 2.7$ \\
\hline
\end{tabular}

Table 2: Mean grain diameter $(\mu \mathrm{m})$

for $\alpha$ and $\gamma$ in the two steels

\begin{tabular}{|c|c|c|}
\hline & $\alpha$ & $\gamma$ \\
\hline UR25N+ & $309 \pm 35$ & $311 \pm 35$ \\
\hline BöA911 & $320 \pm 13$ & $312 \pm 5$ \\
\hline
\end{tabular}

Table 3: Micro hardness HV10 of the two materials

\section{Monotonic plasticity of the DSS UR25N+}

\subsection{Experimental procedure}

For this part of the study, a Veeco Nanoscope III with a silicon nitride pyramidal tip (angle equal to $35^{\circ}$, radius of curvature smaller than $15 \mathrm{~nm}$ ) working in the contact mode has been used. Four flat tensile specimens with a reduced squared section $(2 \mathrm{~mm} \times 2 \mathrm{~mm})$ and $14 \mathrm{~mm}$ in length were electro spark machined from the UR52N+ sheet. Their loading axis was parallel to the rolling direction. Before testing, the specimens were mechanically polished and then electro-polished in a solution containing 70\% acetic acid, $25 \%$ perchloric acid and 5\% water, under $12 \mathrm{~V}$. An UTS electro mechanical machine was employed to plastically deform each specimen to a target deformation, with engineering plastic strain values of $\varepsilon_{\mathrm{p}}=0.2 \%, 0.7 \%, 1.15 \%$ and $1.8 \%$. All tests were carried out at room temperature in air under a controlled cross-head speed of $0.014 \mathrm{~mm} . \mathrm{s}^{-1}$, equivalent to a strain rate of $10^{-3} \mathrm{~s}^{-1}$

The analyzed area had a size of $150 \mu \mathrm{m} \times 150 \mu \mathrm{m}$ and was composed of 9 scanned zones. Each had a size of $50 \mu \mathrm{m}$ x $50 \mu \mathrm{m}$, was formed with 512 lines and 512 pixels per line. These conditions allow a lateral resolution of $98 \mathrm{~nm}$. To correlate the evolution of the deformation induced topography with the microstructure, a FEI Quanta 400 SEM equipped with a HKL EBSD system was employed for a crystallographic description in each phase of the grains involved in the AFM analysis.

\subsection{Identification and interpretation of the slip bands in ferrite and austenite}

Since the solubility of the different chemical elements differs between austenite and ferrite, the local chemical composition in each of the two phases, and therefore the dissolution potential, is also different. During electro polishing, it is impossible to dissolve the same amount of matter in ferrite and austenite, and it is necessary to choose the experimental conditions to approach close dissolution rates in each phase. This was done successfully with the present experimental conditions since the microstructure could be AFM imaged as could be with SEM. The austenitic islands appeared higher than the ferritic matrix and the offset was about 200nm maximum. 
Before tensile straining, no significant roughness was observed in both phases and the background will be used as a reference for the determination of the deformation induced roughness.

After loading, in each deformed specimen, plasticity marks were visible in both phases and the abundance increased with increasing levels of the plastic deformation. Not only was the number of slip bands revealed but also a difference in their morphology depending on whether they were observed in ferrite or austenite. At the surface of the austenite grains, the slip bands were easily observable even at $\varepsilon_{\mathrm{p}}=0.2 \%$, straight and often inclined with the loading axis (Fig. 2). Their length was in general close to the grain size and they crossed while changing their direction the thermal twins embedded in a grain. Increasing the plastic deformation resulted in multiglide associated with the presence of two slip band set within an austenitic grain. The morphology of the slip bands clearly reflects the deformability of the austenite and suggests that the dislocation slip mode is planar, which has been confirmed by TEM.

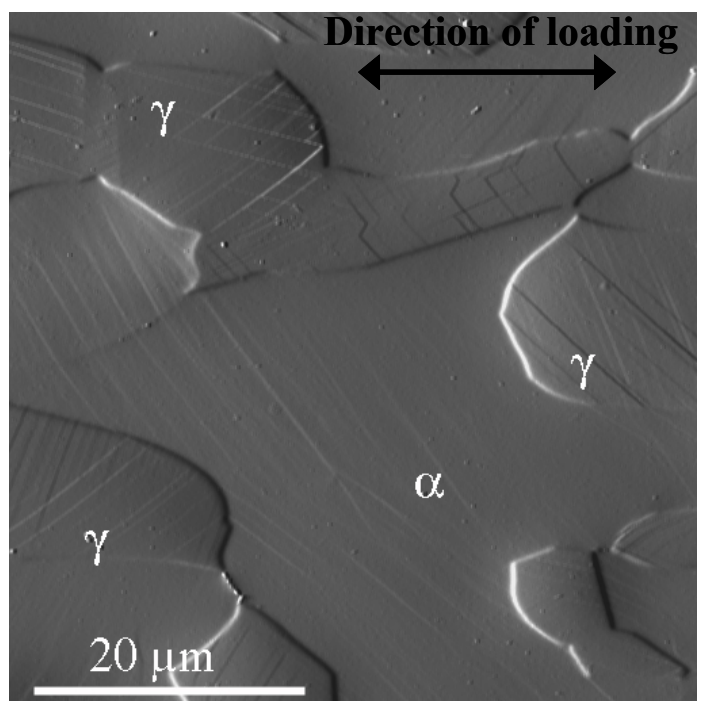

Figure 2 : Signal error AFM micrograph of slip bands in the $\alpha$ and $\gamma$ grains after plastic deformation $\varepsilon_{\mathrm{p}}=1.8 \%$
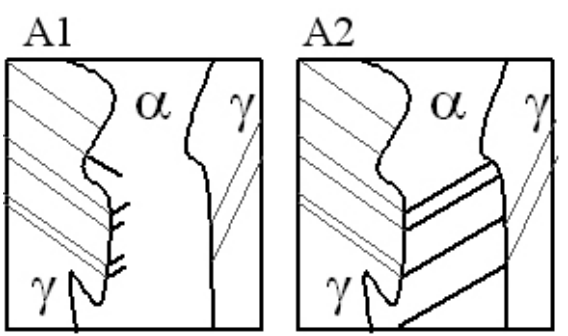

F1

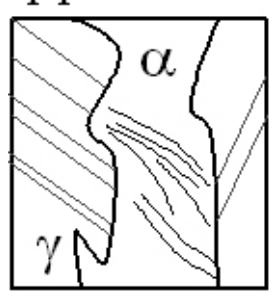

F2

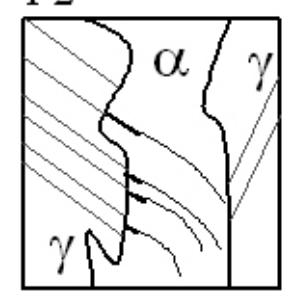

Figure 3: Classification and terminology of the different slip bands observed in the ferrite grains according to their morphology

On the surface of the ferritic grains, slip bands were also observed (Fig. 2) whatever the plastic strain value but according to their characteristics, they could be classified in two groups, as shown in Fig. 3. The first group consists of straight slip bands, type A1 and type A2, resembling those in austenite (Fig. 4). Type A2 had a length of the grain size while type A1 slip bands were shorter and located near the phase boundary. Both type A1 and type A2 were linear and seemed to be connected with the slip bands in the neighbouring austenitic grain. The second group, type F1 and F2 (Fig. 5) consists of more or less curvilinear slip bands, completely different in their shape from those observed in the austenite. Type F1 slip bands were always observed in the middle of the ferritic grain and had a length less than the ferritic grain size so that they did not intersect the phase boundary. However, the type F2 had the characteristic of type F1 except that their extremities were rectilinear and in contact with the phase boundary. Hence, though four kinds of slip bands were identified in the ferrite, it is likely that three of them (A1, A2 and F2) are connected with the neighbouring austenite grain. Conversely, type F1 slip bands seem to originate from the plasticity process developed in the ferrite grains. To confirm this assumption, let us suppose momentary that type F1 slip marks can reflect slip activity in the ferrite or in the neighbouring austenite. Respectively, there are 12 slip systems $(\{111\}<110>$ ) for the face centred cubic structure austenite and $48(\{110\}<111>,\{211\}<111>$ and $\{321\}<111>)$ for the body centred cubic structure ferrite. The principle successfully employed by Fréchard et al.[8], Villechaise et al.[9] and Man et al. [10], consists in calculating the angle between the loading direction and the slip bands associated with each slip system, provided all the crystallographic orientations of each grain have been determined owing to the indexation of EBSD patterns. 

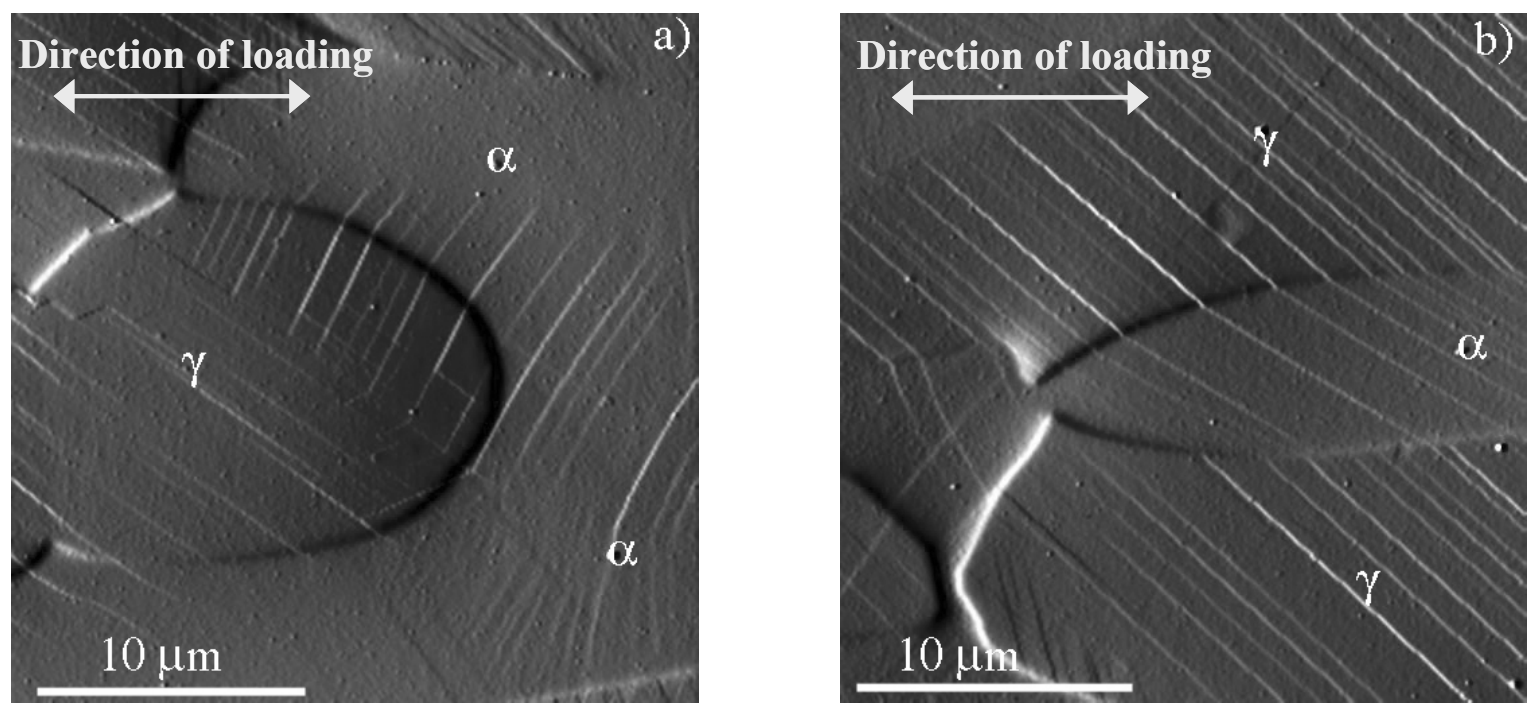

Figure 4: Slip bands in the $\alpha$-grains $-\varepsilon_{\mathrm{p}}=1.8 \%$ - a) type A1, b): type A2 (AFM signal error micrographs)
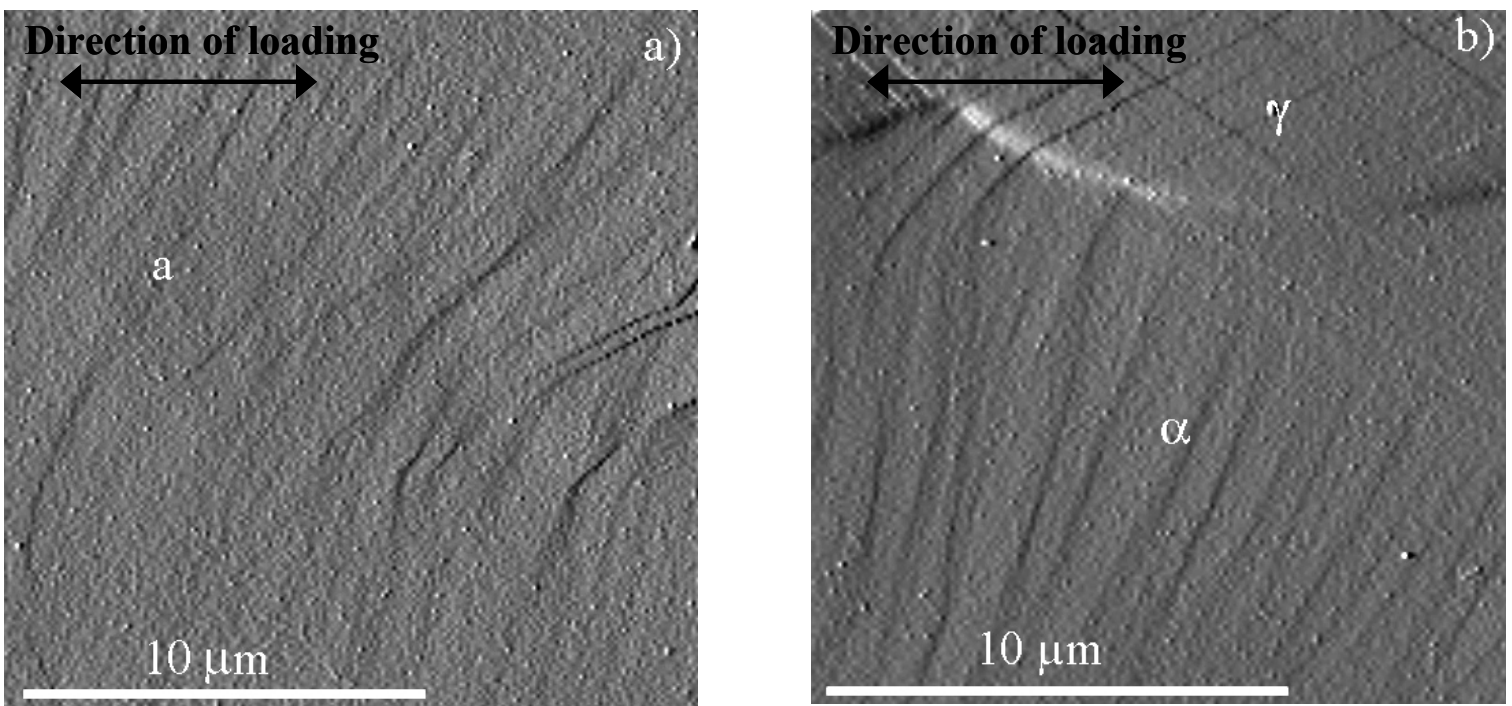

Figure 5: Slip bands in the $\alpha$-grains $-\varepsilon_{\mathrm{p}}=1.8 \%$ - a) type F1, b): type F2 (AFM signal error micrographs)

These calculated angles are then compared with the measured angles between the loading direction and the type F1 slip bands on AFM images. It was found that there was good agreement between the measured EBSD data and the calculated angles when type F1 slip bands were considered in the ferrite phase but poor agreement when the austenite was considered. It can be concluded that type F1 slip bands originate from bulk plasticity in the ferrite in agreement with other authors $[8,11]$. The ability for dislocations in a DSS to transfer from austenite to ferrite depends on their crystallographic compatibility $[11,12,13]$. Especially, for such bcc/fcc system, the Kurdjumov-Sachs (KS) crystallographic relation must be satisfied: $\{111\}_{\text {fcc }} / /\{110\}_{\text {bcc }}$ and $<011>_{\text {fcc }}$ $/ /<111>_{\text {bcc. }}$. In the present case, from the Euler angles obtained by EBSD measurement, the relationship was considered to be satisfied when the angle between the systems was less than $10^{\circ}$. In this way, a ferrite grain is plastically compatible with neighbouring austenite grains and then a slip band formed in the austenite and piling up at the $\alpha / \gamma$ interface leads to deformation in the ferrite by a transfer process. If the plasticity transfer is accompanied by a promoted shear of ferrite, then a straight slip band crosses the ferrite up to the opposite phase boundary (Type A2 slip band). If it is not promoted, then the portion of the slip band in the ferrite either disappears in the vicinity of the phase boundary (Type A1 slip band) or can be extended further by a curvilinear slip band giving 
rise to the type F2 slip band. If a ferrite grain does not exhibit any compatibility with neighbouring austenitic grains, then curvilinear slip bands (type F1) extrude in the middle of the ferrite grain reflecting the self plastic activity of this phase. The results clearly illustrate the complexity of the plasticity mechanisms in duplex steels where one phase can assist the deformation of the other. In the present alloy, the plastic response of the ferrite phase, though it is as soft as austenite, strongly depends on the crystallographic misorientation relation between them. Without any plasticity compatibility between ferrite and austenite, both phases deform independently and type F1 slip bands are observed in ferrite. When a ferrite grain is compatible with one of the neighbouring austenite grains, the deformation of the ferrite grain is controlled by the neighbour austenite and types A1, A2 and F2 slip bands are observed in ferrite.

\subsection{Quantitative repartition of slip bands in ferrite and austenite}

To understand the contribution of each phase to the macroscopic deformation, an AFM statistical study of the phase activity was carried out in an area representative of the whole specimen surface $(150 \mu \mathrm{m} \times 150 \mu \mathrm{m})$. It consists first, from the AFM micrographs, in an accurate counting of the slip bands in each phase as a function of the plastic strain (Fig. 6).

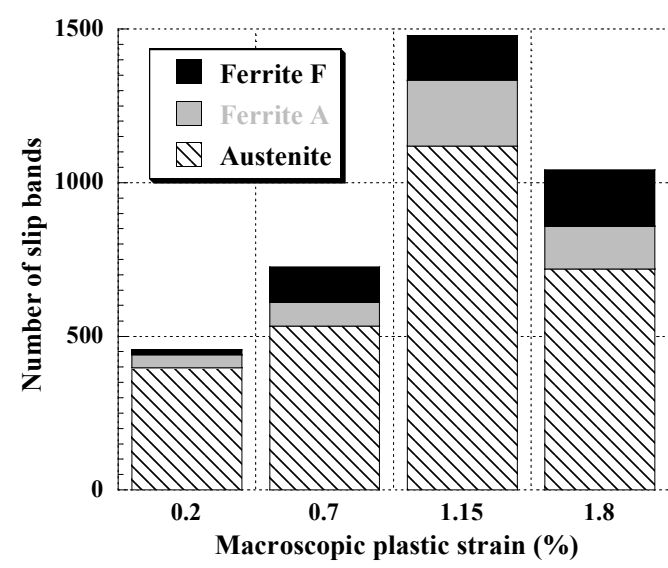

Figure 6: Number of different slip bands in each phase of the duplex steel according to the imposed plastic strain

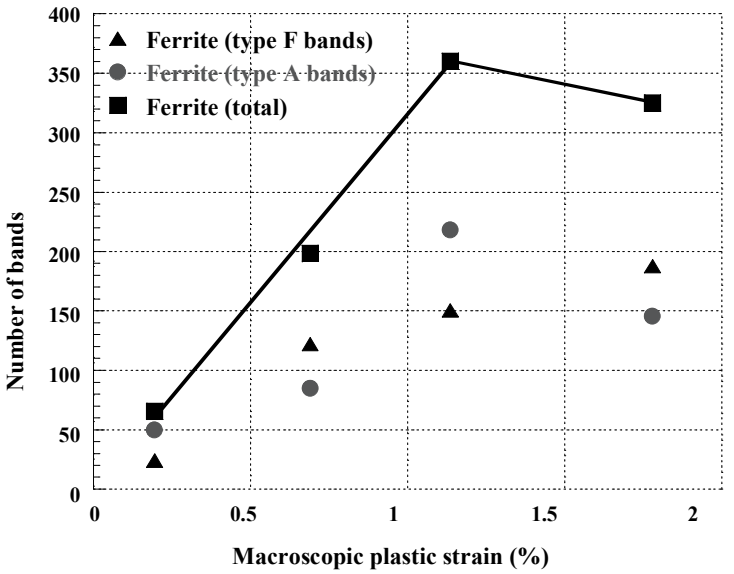

Figure 7: Evolution of the number slip bands in the ferrite phase according to the slip band type (A and $\mathrm{F}$ ) and as a function of the plastic strain

In both the austenite and ferrite phases, the number of slip bands increases with increasing plastic deformation up to $\varepsilon_{\mathrm{p}}=1.15 \%$ and then decreases. Detailed analysis of the ferrite phase has been made taking into account the classification of the type of slip bands described in the previous section, and counting according to the type of slip bands (type A or F) (Fig. 7). A linear increase of the number of type F slip bands is observed but an evolution of the number of type A slip bands similar to what occurred in austenite is noted, an increase followed by a decrease. This decrease is somewhat artificial and can be explained by an evolution of type A1 slip bands to type F2 slip bands with the increment of the plastic deformation. The increasing rate of slip bands with the plastic deformation also suggests that austenite strongly influences the response of ferrite up to $\varepsilon_{\mathrm{p}}=$ $1.15 \%$ while its role is reduced above this.

For the decrease in the number of slip bands in austenite above $\varepsilon_{\mathrm{p}}=1.15 \%$, a similar explanation can be made but there are other factors involved since there was a single type of slip bands in the austenite. The other reason could be provided from the investigation of the high resolution profile of the slip bands according to the plastic strain. At first, the geometry of the slip bands is described in terms of height of the slip bands $\left(\mathrm{H}_{\mathrm{SB}}\right)$ and of distance between the slip bands of a same grain $\left(\mathrm{D}_{\mathrm{SB}}\right)$ (Fig. 8). 


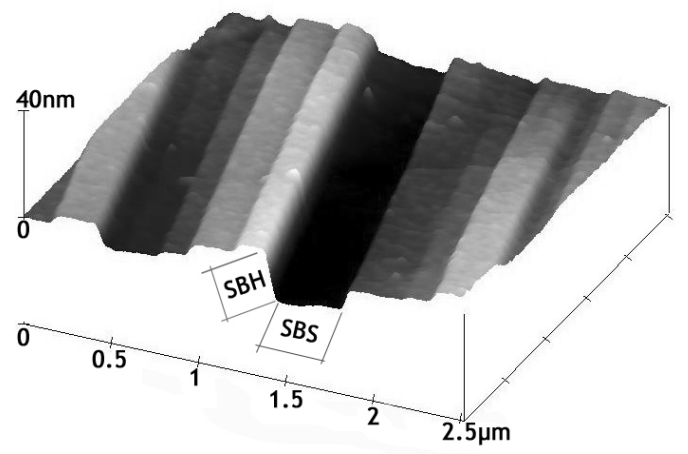

Figure 8: 3-D view of the slip bands in an austenitic grain: profile of the slip bands after plastic deformation $\varepsilon_{\mathrm{p}}=1.15 \%$

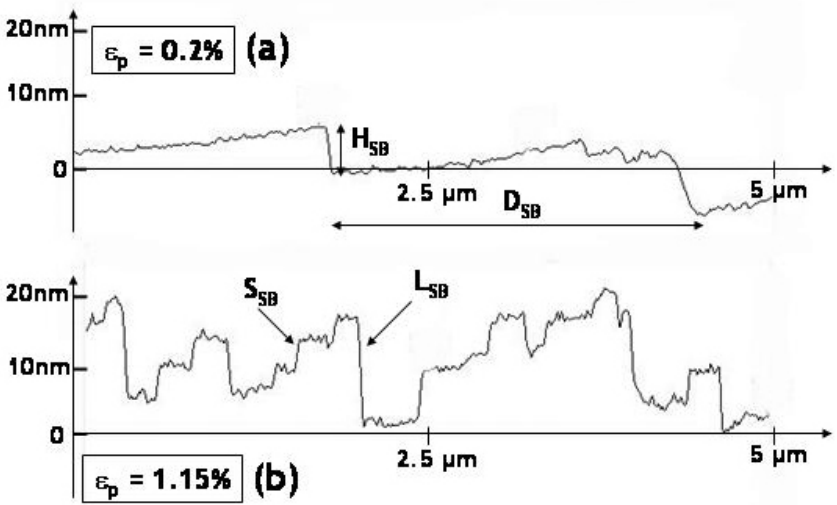

Figure 9: Profile of the slip bands formed in austenitic grains after plastic deformation $\varepsilon_{\mathrm{p}}=$ $0.2 \%$ (a) and at $\varepsilon_{\mathrm{p}}=1.15 \%$ (b)

At low plastic strain $\left(\varepsilon_{\mathrm{p}}<1.15 \%\right)$, the morphology of the slip bands was in the shape of saw tooth (Fig. 9a). SBH and SBS could be measured unambiguously, giving respectively about $4 \mathrm{~nm}$ and $2.5 \mu \mathrm{m}$. At higher plastic strain $\left(\varepsilon_{\mathrm{p}} \geq 1.15 \%\right)$, the shape of the bands appeared more jagged and it was necessary to distinguish the Large amplitude jogs to the Small amplitude ones, namely $\mathrm{L}_{\mathrm{SB}}$ and $\mathrm{S}_{\mathrm{SB}}$ (Fig. 9b). Table 4 gives the evolution of the mean height $\left(\mathrm{H}_{\mathrm{SB}}\right)$ and the mean distance between the slip bands $\left(\mathrm{D}_{\mathrm{SB}}\right)$ with the macroscopic plastic deformation.

\begin{tabular}{|l|c|c|c|c|}
\hline Macroscopic plastic deformation & \multirow{2}{*}{$0.2 \%$} & \multicolumn{2}{|c|}{$1.15 \%$} & \multirow{2}{*}{$1.8 \%$} \\
\cline { 3 - 4 } & & $\mathrm{S}_{\mathrm{SB}}$ & $\mathrm{L}_{\mathrm{SB}}$ & \\
\hline Height of the slip bands $\left(\mathrm{H}_{\mathrm{SB}}\right)[\mathrm{nm}]$ & 11 & 5 & 16 & 17 \\
\hline Distance between the slip bands $\left(\mathrm{D}_{\mathrm{SB}}\right)[\mu \mathrm{m}]$ & 2.5 & 0.25 & 1 & 1.5 \\
\hline
\end{tabular}

Table 4: Evolution of the characteristics of the slip bands in austenite according the macroscopic plastic deformation (see Figures 8 and 9 for definitions of $\mathrm{H}_{\mathrm{SB}}, \mathrm{D}_{\mathrm{SB}}, \mathrm{S}_{\mathrm{SB}}, \mathrm{L}_{\mathrm{SB}}$ )

The apparent decrease in the number of slip bands in austenite from $\varepsilon_{\mathrm{p}}=1.15 \%$ to $\varepsilon_{\mathrm{p}}=1.8 \%$ can therefore be interpreted as an evolution in the geometry of the slip bands with the plastic deformation involving a coalescence of the small slip bands into larger but less numerous ones. In other words, the extruded volume of matter in the austenite is still increasing in the discussed plastic strain range.

\section{Cyclic plasticity}

\subsection{Experimental procedure}

For this second part, a Digital III Atomic Force Microscope in tapping mode with a Veeco anisotropic pyramidal tip MPP-11100 (front angle $15^{\circ}$, back angle $25^{\circ}$, side angle $17.5^{\circ}$ and radius of curvature inferior to $10 \mathrm{~nm}$ ) was used. In order to ensure a representative study, four different areas of $60 \mu \mathrm{m} \times 60 \mu \mathrm{m}$ were analysed (taking into account different local distributions of ferriteaustenite). Four $30 \mu \mathrm{m}$ x $30 \mu \mathrm{m}$ AFM images composed each area. Additionally, in order to increase the lateral resolution of the 3D data and to study in detail some particular surface slip markings, few images were taken at $10 \mu \mathrm{m} \times 10 \mu \mathrm{m}$.

The BöA911 fatigue specimens were flat $3 \mathrm{~mm}$ in thickness, $6 \mathrm{~mm}$ in width and $12 \mathrm{~mm}$ in gage length. Their surfaces were polished using the same conditions described previously, and an electromechanical test machine was employed to cyclically deform the specimen. A symmetrical triangular tension-compression waveform was monitored at a total strain amplitude $\varepsilon_{\mathrm{t}}= \pm 0.8 \%$ and a constant strain rate of $4 \times 10^{-3} \mathrm{~s}^{-1}$. The deformation was measured by means of an extensometer directly attached on the gauge length. Before AFM surface analysis, five cycles were applied and a 
cyclic hardening was observed. The hysteresis loops were recorded from which the plastic strain range was measured as the width of the loop at zero stress. The cumulated plastic deformation range was $5.14 \%$, that is a cumulative amplitude $\pm 2.57 \%$. During cycling, the material exhibited a cyclic hardening e.g. an increase of the stress amplitude from cycle to cycle.

\subsection{Modifications of the surface due to cyclic plasticity}

Cyclically deforming the material resulted in a strong modification of the topography in austenite and a weak one in ferrite. One grain was considered as "active" when surface changes occurred at the surface and as "inactive" otherwise.

After 5 cycles, almost $40 \%$ of the austenitic grains are active. Even if slip lines, similar to that observed after monotonic loading, are the main morphology ( $70 \%$ of the active grains), a mixed mode combining slip lines together with fatigue extrusions is already noticeable (Fig. 10). The slip lines are steps of 10 to $20 \mathrm{~nm}$ in mean height, and seem to serve as nucleation sites for the mixed morphology.

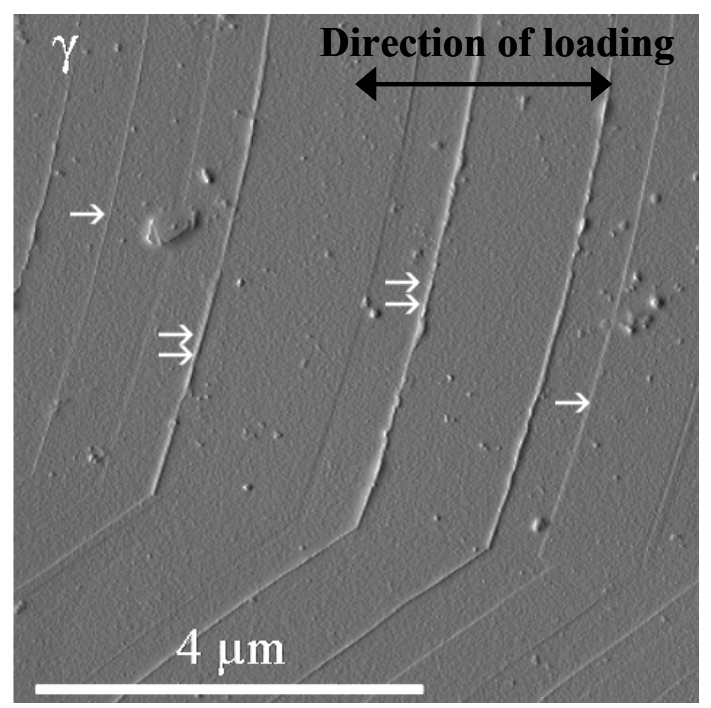

Figure 10: Slip line $(\rightarrow)$ and mixed morphology $(\rightrightarrows)$ observed in $\gamma$ phase after 5 cycles AFM signal error micrograph

Surface activity in ferrite was evident in only $20 \%$ of the grains. The only surface features observed in active grains are slip traces resembling type $\mathrm{F}$ slip bands described for the monotonic loading: isolated curvilinear slip bands (type F1, Fig. 11a) located in the interior of the $\alpha$-grains and curvilinear slip bands with a rectilinear extremity connected to a slip band or an extrusion of the neighbouring austenite grain (type F2, Fig. 11b).

The present investigation shows that the plasticity marks developed during the first quarter of cycle rapidly modify with further loading and unloading at the surface of the austenitic grains but not for the ferritic grains. Since the slip bands evolve to fatigue extrusions, this clearly demonstrates that the total plastic deformation is mostly accommodated by the austenitic phase and weakly the ferritic phase. Though ferrite contained type F1 and type F2 slip bands, reflecting an effect of austenite on ferrite deformation, a striking difference was observed between the topography after monotonic deformation and cyclic deformation with the ferrite free of type A slip bands (straight slip bands) after fatigue. This can be explained by two motives. Though the average stress - strain response is the same for both DSS, the partition of plastic deformation from austenite to ferrite is not necessarily the same as a result of the relative ability of each phase to plastically deform. As noted in the previous section, the monotonic plasticity of the ferrite strongly depends on the crystallographic misorientation between the ferrite and austenite, and therefore of the crystallographic textures of austenite and ferrite. These, especially for ferrite, are very sensitive to the working process, which in the present study differs between the two alloys. In other words, a likely difference in crystallographic texture between the two studied alloys would promote the 
contribution of $\gamma$ phase in the deformation process of $\alpha$ grain in the UR52N+ but not for the BöA911. In addition to this explanation based on crystallographic orientations, it is also reasonable to consider Nakai's observations [14]. In the initial stage of fatigue, slip bands can be formed only under tension or only under compression. These slip bands observed by Nakai with AFM during interrupted fatigue tests, disappear and are not associated with cyclic plasticity. It can be assumed in the present study that the straight slip bands formed during the first quarter cycle of the fatigue test may disappear with further cycling. Moreover, this suggests that only extrusions have to be considered for the localization of cyclic plasticity. Their absence in the ferrite phase would express that $\alpha$ phase does not accommodate the cyclic plasticity during the first 5 cycles.
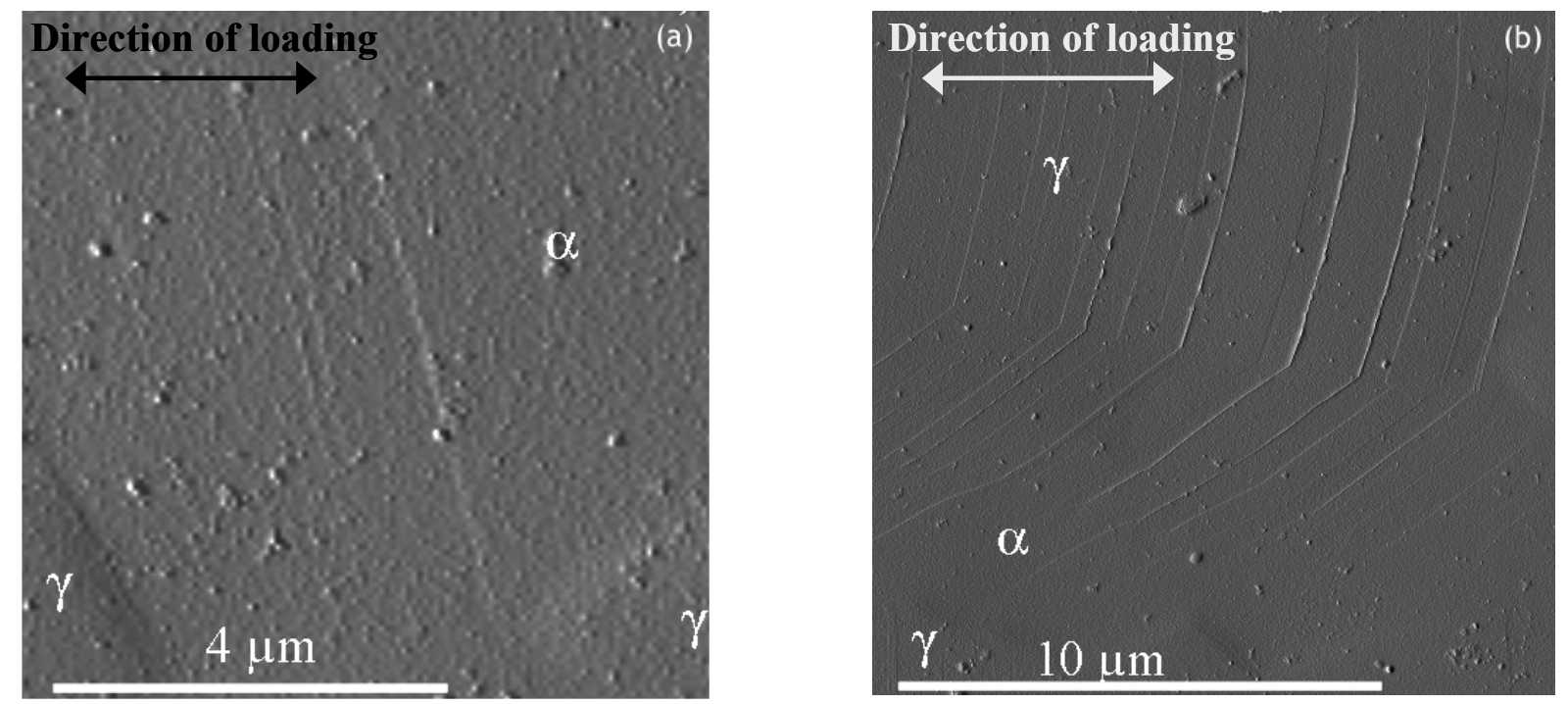

Figure 11: slip bands in $\alpha$ phase after 5 cycles - a) type F1, b): type F2

(AFM signal error micrographs)

\section{Conclusions}

In this work, Atomic Force Microscopy was used to study the plasticity markings in separate phases of a Duplex Stainless Steel to identify their individual contribution to the macroscopic mechanical response and their interaction. The AFM analyses of surface relief evolution of tow Duplex Stainless Steels subjected to monotonic or cyclic plastic deformation allow us to draw the following conclusions:

- After monotonic loading, austenite develops straight slip bands which serve as fatigue extrusion nucleation sites observed.

- In ferrite, after monotonic deformation, straight slip bands initiate from the deformation of austenite and curvilinear slip bands form the plastically deformed ferrite bulk

- The monotonic plasticity of ferrite assisted by austenite depends on the crystallographic orientation between the austenite and ferrite grains.

- Applying five fatigue cycles leads to cyclic plasticity marks in austenite but not in ferrite. This suggests a total accommodation of the cyclic plasticity by austenite.

\section{References}

[1] J. Schwab, J. Bretschneider, C. Buque C. Blochwitz and C. Holste: Philosophical Magazine Letters Vol.. 74 (1996), p 449

[2] H.J. Leber, M. Niffenegger and B. Tirbonod: Materials Characterization Vol 58 (2007), p 1006 
[3] V. Vignal, E. Finot, R. Oltra, Y. Lacroute and E. Bourillot, Alain Dereux: Ultramicroscopy Vol 103 (2005), p 183

[4] J. Polak, J. Man, K. Obrtlik and T. Kruml: Z. metallkunde Vol 94 (2003), p 1327

[5] C. Wejdemann and O.B. Pedersen: Materials Science and Engineering A Vol 387-389 (2004), p 556

[6] M. Ménard, J.M. Olive, A.M. Brass and I. Aubert in : Proc. $2^{\text {nd }}$ Int. Conf. on Induced Cracking of Metals (EICM2) vol.1, p.179

[7] J-B Vogt: Journal of Materials Processing Technology Vol 117 (2001), p 364

[8] S. Frechard, F. Martin, C. Clément and J. Cousty: Materials Sciences and Engineering A Vol 418 (2006), p 312

[9] P. Villechaise, L. Sabatier and J-C. Girard: Materials Science and Engineering A Vol 323 (2002), p 377

[10] J. Man, K. Obrtlík, C. Blochwitz and J. Polák: Acta Materialia Vol 50 (2002), p 767

[11] A. Taisne, B. Decamps and L. Priester: Composites Interfaces Vol 13 (2006), p 89

[12] I. Alvarez-Armas, M.C. Marinelli, J.A. Malarria, S. Degallaix and A.F. Armas: International Journal of Fatigue Vol 29 (2007), p 758

[13] S. Bugat, J. Besson, A-F. Gourgues, N'Guyen and A. Pineau: Materials Sciences and Engineering A Vol 317 (2001), p 32

[14] Y. Nakai, K. Ohnishi and T. Kusukawa in: ASTM Special technical publication (2000), p 122 